\title{
Autoficción en la novela El orden del mundo
}

Juan Pablo Chiappara

Professor DE na área de Literatura hispano-americana do Departamento de Letras da Universidade Federal de Viçosa (UFV). Tem sraduação em Língua, Literatura e Civilização Estrangeiras: Espanhol (Paris III); Mestrado em Análise do Discurso (UFMG) e Doutorado em Literatura Comparada (UFMG). Pesquisa e orienta na área de Literatura hispano-americana dos séculos $X X$ e $X X \mid$ i é autor de artigos em revistas e coletâneas, e de Ficciones de vida. La literatura de Carlos Liscano (Montevideo, 2011). Atualmente é Chefe do Departamento de Letras, e editor da Revista ELO - Diálogos em Extensão, da UFV.

Contato: juanpablochiappara@

Recebido em: 11 de maio de 2018 ufv.br

Aceito em: 13 de agosto de 2018 Brasil 


\section{PALABRAS CLAVE:}

Biografía; Bio/srafía;

Autoficción; Auto/ficción;

Novela

KEYWORDS: Biography;

Bio/sraphy; Autofiction;

Auto/fiction; Novel
Resumen: Este artículo analiza El orden del mundo de Ramiro Sanchiz desde la perspectiva de la autoficción. Analizamos dos elementos de la novela: la idea del libro total y la complejidad del narrador. Este análisis, aliado al concepto de bio/grafía de Maingueneau, nos permite reflexionar sobre la deconstrucción de novela y autobiografía al no aceptarlas como polos antitéticos en lo que concierne a la representación del yo autoral. También dialogamos con autores que discuten desde una perspectiva teórica el concepto de autoficción en El yo fabulado (Casas, 2014). Ese diálogo nos conduce a suserir el abandono de la perspectiva que considera la autoficción como sénero o subsénero literario. Proponemos un desplazamiento semiótico del término autoficción hacia auto/ficción en el cual la barra expresa la opacidad, inestabilidad y reciprocidad constitutivas en la relación que se establece entre el yo autoral y el texto al redactar un manuscrito que recaerá en algún punto del espectro que va de la autobiografía a la novela.

Abstract: This paper analyzes El orden del mundo by Ramiro Sanchiz from the perspective of autofiction. We andyze two elements in the novel: the slobal idea of the book, and the narrator's complexity. This analysis, combined with Mainguenau's bio/graphy concept, allows us to ponder over the deconstruction of the novel and of autobiography by not accepting them as antithetical poles as far as the capacity of representing the authorial I goes. Second, we dialogue with scholars who discuss, from a theoretical perspective, the autofiction concept in El yo fabulado (Casas, 2014). This dialogue yields our sugsestion to abandon the perspective that considers autofiction a literary genre or subsenre. We propose a semiotic displacement of the term autofiction towards auto/fiction, in which the slash expresses the opacity, instability and reciprocity that constitute the relationship that comes to be between the authorial I and the text when we deal with writing a manuscript that will fall somewhere within the autobiography-novel interval. 
El objetivo en este artículo es analizar la novela El orden del mundo del uruguayo Ramiro Sanchiz ${ }^{1}$ (2014; 2017) ${ }^{2}$ desde la perspectiva de la autoficción. Nos interesa entender de qué modo se encaja o de qué manera se distancia esta novela en relación con lo que ya podemos llamar una tradición de lo autoficcional, en la cual cada vez más son inscriptas obras divergentes entre sí, pero reagrupadas por lecturas convergentes, que han ido difuminando las fronteras de la autobiografía y la novela, así como de todo lo que cabe entre ellas.

En suma, tratamos de responder de qué modo el universo del yo autoral permea la novela fantástica de Sanchiz. Una advertencia mayor sobrevuela, sin embargo, nuestro trabajo y no nos deja perder de vista que al tratar de responder dicha pregunta es imposible olvidar que el yo ha sido deconstruido sobre todo a lo largo del siglo XX y, por atenernos solo a la segunda mitad, en particular por el proceso deconstruccionista puesto en marcha por la llamada french theory, forjada en los campus estadounidenses bajo la influencia de algunos filósofos como Foucault, Derrida y Deleuze (Cusset, 2008). En esa línea, Jorge Volpi propone que: “(...) el yo es una novela que escribimos, muy lentamente, en colaboración con los demás.”

1 Ramiro Sanchiz (Montevideo, 1978) lleva una década publicando cuentos y novelas dentro de lo que denomina Proyecto Stahl debido al nombre del protagonista y a veces narrador Federico Stahl. Es posible encontrar más información general sobre este aspecto en trabajos que publicamos anteriormente. (Chiappara, 2016; 2017)

2 Publicada primero en Bolivia por la editorial El cuervo en 2014, recibió en 2016 el Primer Premio Nacional de Literatura en Uruguay, donde fue editada con algunas modificaciones por la editorial Fin de Siglo en 2017. En este trabajo citamos la segunda edición. 
(Volpi, 2011, p.73), mientras que Paul B. Preciado, dentro del ámbito de la filosofía que reflexiona sobre la identidad y la identificación, propone que la escritura es, antes que nada, una tecnología de producción de subjetividad, una intervención sobre uno mismo (Preciado, 2014). Esta forma de comprender el yo como una instancia en constante construcción que no admite entenderlo como unidad de sentido previa no puede ser perdida de vista al plantear el problema de la autoficción. Específicamente en literatura, el quid del asunto parece estar en la articulación que exige y la contradicción que supone la presencia del yo del autor (hecho de fragmentos de incalculables microficciones sobre sí) en una ficción que reconocemos efectivamente como fingimiento consciente.

Teniendo esto en vista, proponemos abordar la autoficción en la novela El orden del mundo de dos maneras.

La primera de ellas consiste en consignar y señalar dos elementos que proponemos como claves en la novela y que analizamos solo en relación con el punto central anunciado. Son ellos: (i) el flirteo con la idea moderna del libro total; (ii) el manejo y la complejidad del narrador. Para alcanzar nuestro objetivo, estos dos elementos son analizados en diálogo con la perspectiva teórica que supone el concepto bío/grafía de Dominique Maingueneau. Para él, "O que se deve levar em consideração não é a obra fora da vida, nem a vida fora da obra, mas sua difícil uniáo." (Maingueneau, 2001, p.46). De hecho, para designar la dimensión constitutiva de cualquier creación, es decir, el hecho de que la escritura engloba la vida y la vida engloba la escritura, propone hablar de: “(...) bio/ 
grafia, com uma barra que une e separa dois termos em relação inestável. 'Bio/grafia' que se percorre nos dois sentidos: da vida rumo à grafia ou da grafia rumo à vida." (Maingueneau, 2001, p.46); lo cual lo lleva a concluir que el “(...) ato de escrever, de trabalhar num manuscrito, constitui a zona de contato mais evidente entre 'a vida' e 'a obra.” (Maingueneau, 2001, p.47). En definitiva, en este primer momento del artículo, dotados de esta herramienta teórica, buscamos reflexionar dentro de la esfera de lo autoficcional problematizando la relación de lo biográfico con lo bío/ gráfico.

La segunda manera mediante la cual hacemos frente a la pregunta central de este trabajo consiste en pensar de qué modo puede encajarse la novela de Sanchiz específicamente en el panorama actual de la autoficción. Para ello, dialogamos con lo que proponen las investigaciones compiladas en El yo fabulado. Nuevas aproximaciones críticas a la autoficción (2014), aunque como substrato de nuestro análisis también estén presentes las perspectivas propuestas en Escrituras del yo: conjeturas (2013), que no desarrollamos por falta de espacio, pero que consideramos relevantes para la discusión de autoficción que proponemos. Si éste es un concepto con entrada enciclopédica, autor y fecha de nacimiento (creado en 1977 por Serge Doubrovsky) y más restringido a lo literario, el sintagma nominal escritura del yo, por su parte, tiene una historia más reciente y difusa, y busca abarcar una serie de fenómenos de representación del yo que exceden o pueden exceder el campo estricto de la ficción al englobar también los diarios, las memorias, la autobiografía, la confesión, el testimonio, la 
denuncia, entre otros posibles textos, escritos u orales. La sobreposición que suele hacerse entre autoficción y escritura del yo nos interesa porque puede ser una forma de plantear el problema de si autoficción debe ser entendida como género o subgénero o, en cambio, como uno de los posibles modus operandi de la presencia del yo en el amplio espectro de textos que caracterizan la narrativa contemporánea.

Abocándonos a la primera manera anunciada para nuestro análisis crítico, en relación con el elemento (i), el lector de El orden del mundo que conozca las ambiciones de Sanchiz, así como algunas de sus declaraciones, no puede dejar de ver el doble flirteo que se hace presente en esta novela en relación con la idea mallarmeana de libro total. Doble porque remite tanto a un aspecto específico de la dimensión narrativa de la novela en pauta, cuanto a la dimensión de totalidad que reivindica el proyecto Stahl como un todo. En lo estrictamente narrativo con relación a El orden del mundo, al diario que escribe Federico Stahl en la isla de basura del Atlántico norte (donde ha naufragado tras la pista de un avión MiG-25, que debe rescatar para llevárselo a quien lo ha contratado para dicha tarea) se lo postula como la ambición de registrar todo lo que sucede en dicha isla, aunque en realidad el diario se desborda hacia una reconstrucción que pretende ser total de la trayectoria de vida del náufrago, quien, a su vez, se ve impelido a narrar porque la propia isla se presenta como un vórtice donde han convergido 
objetos clave de toda su vida que lo interpelan, y precisa ordenarlos en un relato. Es por ese mecanismo argumentativo que el diario flirtea con la utopía mallarmeana del libro total, respaldada por una perspectiva fantástica que apuesta por una totalidad garantizada por la posibilidad de tiempos y espacios simultáneos que redoblan la problemática de la autoría del diario escrito por Stahl en la novela, así como redoblan su condición intermediaria entre realidad y ficción en la propia diégesis de la novela, como se verá, y del ficticio diario, como se puede ver en este fragmento:

El autor del diario, entonces, señalaba que en el mapa de Mercator de la Tierra cabían todos los mundos posibles, y después de citar al Borges de "La biblioteca de Babel" y razonar con él que el número de mundos posibles no podía ser infinito (...) aunque eventualmente, y aquí creo que podría refutar al autor del diario y establecer, acaso comprobar que somos mentes distintas o, en última instancia, dos momentos distinguibles en la evolución de una mente, eventualmente, decía, deberíamos llegar al momento inmediatamente posterior al Big Bang y establecer que (...) está claro entonces que el número de universos posibles es infinito y que (...) infinitos universos accedieron a la existencia solo para satisfacer la totalidad de las posibilidades permitidas o incluso requeridas. (Sanchiz, 2017, p.97)

El juego literario que eso supone creemos que se cruza también con la idea de redactar "otro" libro total, el que el propio proyecto Stahl ambiciona ser. Ese efecto de mutua remisión entre el diario y la macronovela (tal como Sanchiz denomina a su propio proyecto) está dado por el efecto que produce el difuso y múltiple personaje-narrador Federico Stahl, quien 
escribe el diario, pero se vuelve a su vez múltiple e inaprehensible en el sentido de que quien dice yo no remite a un único sujeto externo al lenguaje del diario manuscrito en la isla, como veremos más adelante. Pero la pregunta que se le impone a nuestro objetivo es saber cómo nos conduce esta problemática a considerar la autoficción en El orden del mundo.

Toda obra es o puede ser acogida, por lo menos al nivel de comprometimiento de escritores como Sanchiz, como una bío/grafía, como propone Dominique Maingueneau (2001; 2004), es decir, como una escritura que, conforme se realiza, realiza una vida. Basándonos en este presupuesto, proponemos que leer una obra desde lo bío/gráfico implica atribuir al gesto de escritura una doble función que es performática y performativa; performática en el sentido que involucra a un actor (autor) y sus performances sociales, algo que puede ser vinculado a lo que proponía Gérard Genette con el concepto epitexto (Arroyo Redondo, 2014, p.1274); pero también es performativa como consecuencia de una forma de entender la escritura basada en la pragmática, es decir, en aquello que propusieron Austin y Searle al entender todo acto de lenguaje como una forma de acción.

Lo autoficcional (articulado entre el tema del libro total y los cruces que se producen entre el diario en la ficción, la novela que leemos y el proceso de escribir el manuscrito) en El orden del mundo se articula de forma clara cuando el narrador nos cuenta en la primera página el vínculo directo entre el diario escrito en la isla y un cuaderno forrado de azul escrito por Sanchiz alrededor de sus siete años: 
Sobrevivió incluso un cuaderno forrado de azul - como de mi tiempo en la isla sobrevivió apenas un diario - en el que yo había copiado extensos bloques de textos tomados de la Enciclopedia de Cousteau para complementarlos con dibujos de mi autoría (...). Todo este proyecto del cuaderno azul y las fichas obedecía al propósito, que nunca me ha abandonado, de acceder, así sea escribiéndolo, a un libro total, un compendio de todo lo que existe en el universo (...). (Sanchiz, 2017, p.7-8, cursiva en el original)

Entender esto desde lo bío/gráfico supone creer que los discursos atraviesan y constituyen a los sujetos que deambulan como personas y personajes a un lado y al otro de la frontera que suponen los elementos que forman el concepto autoficción. En la novela, el lector no puede saber exactamente dónde empieza y dónde termina la representación del yo autoral como persona y como personaje reflejados e inscriptos en la diégesis. Además, ese yo puede ser entendido como una caja de resonancia que da voz a muchas voces. Lo que parece que tenemos que entender es que Sanchiz siempre estuvo escribiendo el libro total, desde que empezó a escribir a los siete años en su cuaderno azul y dicho libro sigue siendo escrito en cada novela, y en el El orden del mundo, por medio de un diario ficticio, que representa al mismo tiempo hechos y deseos, acontecimientos biográficos y fantasías vividas como bío/gráficas.

Esto nos conduce al segundo elemento dentro de la primera manera anunciada de abordar El orden del mundo al principio de este trabajo: (ii) el manejo y la complejidad del narrador. 
El diario que Federico Stahl escribe en la isla registra la voz de un narrador que se sabe cumpliendo dicha función y que se identifica con el yo que asume la autoría de dicho diario, lo cual le permite tomar distancia ante lo registrado, pero no le impide creer en la posibilidad de registrar como lo haría un testigo exento y con plenos poderes de observación objetiva de la realidad: “(...) yo me sentía capaz de abarcar el pensamiento, la posibilidad del pensamiento o el saberlo todo, acaso accediendo a ese libro total del que ya he hablado (...)" (Sanchiz, 2017, p.84)

Pero ¿quién escribe este diario?: "En cualquier caso, la lectura del diario deja claro que su autor, que su protagonista, o incluso yo mismo, ocupamos con la exploración de la isla las primeras semanas (...)" (Sanchiz, 2017, p.105-106) Esta oscilación en la autoría es mencionada a lo largo de la novela y la vuelve un punto central: "El autor del diario, entonces, señalaba [...]" (Sanchiz, 2017, p.97); "De esa historia uno de los momentos centrales es la de nuestras (del autor del diario y mías) primeras experiencias [...]" (Sanchiz, 2017, p.110); "Durante esos días, entonces, me sentía el habitante de un vasto laberinto que solo meses atrás había sido confundido con el mundo. Y en la página 54 del diario, día 41 de la estadía del autor y de la mía en la isla [...]" (Sanchiz, 2017, p.114); y así podríamos citar otras ocurrencias donde queda claro que el narrador Stahl anunciado al principio no puede ser realmente considerado un único Stahl pues la pregunta sobre quién narra en el diario lleva a que se entienda que hay otra pregunta más apremiante: ¿quién narra en esta novela? 
Para responder es necesario tratar de "poner orden" y para ello necesario consignar aquí que la estructura general de El orden del mundo la divide en tres partes: "La enciclopedia del mar", "El orden del mundo" y "La confusión". Entre la primera y la tercera parte se va gestando un enmarañado de voces narrativas que en la propia escritura van gestionando el tema del narrador. Si en la primera parte podríamos decir que quien narra es un alter ego de Sanchiz que designaremos como plano, que mezcla recuerdos autobiográficos de su infancia con imaginación para construir la infancia de Stahl; y si en la segunda parte podríamos decir que quien narra es un alter ego un poco menos plano que va ganando tridimensionalidad narrativa como voz que enreda de forma más literaria la imaginación de Sanchiz con su memoria vital; en la tercera parte lo que éste nos entrega es, como el título lo sugiere, una síntesis que confirma una mise en abyme estructural.

Dicho efecto se produce cuando el lector de la novela toma conciencia de que el narrador del diario en la diégesis se enreda con el narrador de la novela que tenemos en las manos. Ese vaivén es también otra de las claves que constituyen la poética de El orden del mundo, lo cual la hace participar plenamente de la problemática colocada por el concepto autoficción:

Recuerdo también que cuando me preguntaban que estaba escribiendo yo respondía que se trataba de una novela larguísima y ambiciosa, que bien podía llevarme toda la vida. Y algo de eso aparece en el diario, en una de las secciones dedicadas a exponer la lectura del conjunto de novelas de ese o esos Federicos Stahl alternativos, la idea de una serie de novelas y 
nouvelles encadenadas en una suerte de macronovela, entendida como una obra interminable (...). (Sanchiz, 2017, p.102, cursiva en el original)

En conclusión, no hay duda de cómo ese vaivén entre diario, novela, lector del diario y nosotros lectores de la novela se imbrica de tal modo que nos coloca delante de un elemento autoficcional como es la escritura del Proyecto Stahl (cuyo eco resuena en la ficción de la novela y del diario, o sea, una mise en abyme), que Sanchiz lleva adelante desde sus publicaciones de cuentos, novelas cortas y novelas que inicia en 2008 (o tal vez desde los siete años), sumando al día de hoy una veintena de títulos publicados en diferentes plazas editoriales.

El segundo bloque de este trabajo trata de la segunda manera de abordar la novela El orden del mundo que anunciamos al principio. Se trata aquí de evocar algunas discusiones teóricas sobre la autoficción y pensar de qué manera se acerca o se aleja esta novela de las posibles definiciones de lo autoficcional. Para ello dialogamos con la obra colectiva El yo fabulado. Nuevas aproximaciones críticas a la autoficción (Casas, 2014), que reúne trabajos de especialistas hispanistas de varias universidades europeas. Lo arduo de evocar los debates que esta obra condensa es poder dar cuenta en un breve espacio de todos los matices propuestos. Por lo tanto, nos resignamos a dialogar con algunos puntos de vista de algunos de los textos e invitamos al lector a comprobar la calidad de todos ellos. 
Una vez señalado el nacimiento del concepto autoficción, propuesto por Doubrovsky en 1977 en la novela Fils, cabe entender de qué modo ha ido desdoblándose lo que dicho concepto implicó en aquella época. Arnaud Schmitt sugiere que el punto culminante de esta aventura teórica habría sido dado por la obra Autofiction. Une aventure du langage, de Philippe Gasparini, publicado en 2008, quien afirma que el éxito del término autoficción habría sido garantizado por su capacidad de subvertir la distinción entre ficción y autobiografía (Schmitt, 2014, p.791). Esta afirmación, a pesar de ser verdadera por apuntar a un amplio espectro que difícilmente no acertaría el blanco, sin embargo, nos parece que no considera algunos problemas teóricos más generales, no específicos del ámbito de los géneros o subgéneros literarios, sino provenientes del pensamiento de índole filosófico e interdisciplinar. De hecho, todavía nos parece necesario, cuando leemos algunas posturas más conservadoras sobre la autoficción, relativizar definiciones de ficción y de autobiografía que las proponen como realidades auto explicativas gracias a alguna cualidad intrínseca que les sería auto evidente.

Ahondar en esta duda que nos suscita la definición de autoficción significa sugerir que su fecha de nacimiento no es para nada casual, sino que debe ser situada en un contexto como el francés de los años 1970 cuando se habían consolidado los principios estructuralistas en todo el espectro del lenguaje, incluidos los estudios literarios. Lo intransitivo reinaba en el ámbito de la crítica, así como de la teoría, y erigía en anatema la idea de que el autor pudiese autorepresentarse o siquiera estar oblicuamente 
presente en una narrativa ficcional. La cuestión del autor venía siendo planteada de forma específica desde la década anterior como lo vuelven evidente los famosos textos "La muerte del autor", de Barthes, 1967, y "Qué es un autor", de Foucault, 1969. Barthes afirmaba en su texto que “(...) l'écriture est destruction de toute voix, de toute origine. L'écriture, c'est neutre (...)"(Barthes, apud Alarcón, 2014, p.2194). Foucault, por su parte, en respuesta a Barthes, proponía que el autor era una función del discurso y no una presencia biográfica en el discurso.

Javier Ignacio Alarcón (2014, p.2139) nos recuerda que el propio Doubrovsky escribe en respuesta a la postura que Philippe Lejeune defiende en el artículo "El pacto autobiográfico", de 1975, al afirmar que, si bien nada impide que el personaje principal de una novela tenga el mismo nombre que su autor, esto excluye la posibilidad de la ficción. Es contra esta fuerza negativa poderosa que alguien como Doubrovsky va a proponer la idea basada en la hibridez que supone su concepto.

Aún hoy en día, si nos basamos en las discusiones propuestas en $E l$ yo fabulado. Nuevas aproximaciones críticas a la autoficción (CASAS, 2014), es posible percibir que, aunque se buscan nuevas formas de pensar los problemas que plantean nuevos corpus que llevan a pensar en la autoficción como un problema central de nuestra época, una pregunta perdura y consiste en querer responder de qué modo autoficción estaría mucho más cerca de lo autobiográfico que de lo novelesco. Al contrario de esta perspectiva que nos parece restrictiva, nos sentimos cercanos a lo que propone el norteamericano David Shields en su libro Reality Hunger: $A$ 
Manifesto, de 2010: "En esta obra, el autor defiende con brío la tesis de un género no determinado y propone abandonar la vertiente de la racionalidad genérica. Al ser americano, no utiliza nunca el término autoficción (...)." (Schmitt, 2014, p.875)

A partir de ahí, Schmitt resume las ideas de Shields, siendo que la que nos interesa en este caso es la más radical: el rechazo de la dicotomía real/ ficción, que el propio Schmitt (2014, p.875) confiesa que le cuesta aceptar.

Pero si tomamos esta idea no como un presupuesto ya asumido, sino como una hipótesis de trabajo, creemos que hacemos más por la reflexión en torno a la autoficción que si nos limitamos a pensarla como un subgénero, en vez de entenderla como una fuerza que oscilaría en grados diferentes entre la autobiografía y la novela, socavando lo que comúnmente se les atribuye como esencial a estas dos formas de narrativa.

En nuestro caso, el postulado radical de Shields (que por ahora no consideramos ni verdadero ni falso) nos sirve como parámetro para proponer nuestra manera de entender la autoficción a partir de la novela en cuestión, puesto que nos parece necesario destacar que son las obras las que acaban por desplazar cualquier concepto teórico. Entre ellas, pues, El orden del mundo es indudablemente una novela, la cual, no obstante, creemos que funciona gracias a una contaminación de lo autoficcional, que resulta ser clave porque lo es en la macronovela llevada adelante por el proyecto Stahl. En resumen, creemos que el caso de Sanchiz se encaja en la autoficción tal como propone pensarla Schmitt cuando la entiende 
como "(...) una manera personal de organizar la vivencia en experiencia narrativa;" (Schmitt, 2014, p.1140)

Lo que propone Shields nos interesa también porque corrobora nuestra intuición con relación a la manera como la autoficción se puede adscribir a la novela estudiada de Sanchiz, o sea una manera de entenderla cuyas claves están, aunque resumidas, en la primera parte de este trabajo. Estas claves consisten en pensar la autoficción no tanto (o no solo) como un fenómeno que pone en evidencia la dimensión ficticia del yo biográfico, sino sobre todo como yo bío/gráfico porque vida y escritura se coconstituyen. Por eso, también nos adscribimos a lo que concluye Schmitt sobre autoficción desde el plano teórico:

(...) estudiar una transformación del yo en relato más ambiciosa desde el punto de vista literario en la medida que integra la virtualidad de nuestra vida psíquica, explora la figura del autor y piensa la identidad directamente en relación con el texto que la exhibe, y no como una entidad que le preexiste. (Schmitt, 2014, p.1151)

Siguiendo esta lógica y estirando sus posibilidades, al sugerir la relación entre lo auto (el yo) y la ficción (la alteridad) que contiene autoficción, proponemos desplazar la estructura semiótica del concepto respaldándonos en la idea de bío/grafía que propone Maingueneau y sugerimos el término auto/ficción. Con ello pretendemos llamar la atención sobre la necesidad de tomar distancia de las definiciones naturalistas del concepto como por ejemplo la que propuso Jacques Lacarme en 1993: “(...) l'autofiction 
est d'abord un dispositif très simple: soit un récit dont auteur, narrateur et protagoniste partagent la même identité nominale et dont l'intitulé générique indique qu'il s'agit d'un roman (...)" (Lecarme, apud Arroyo Redondo, 2014 , p.1263). En oposición a esta idea, la barra de auto/ficción pretende poner de relieve una relación inestable y opaca en la manera como el autor inscribe fragmentos del relato sobre sí mismo al cual tiene acceso y del cual sabemos que su esencialidad ficcional es función de la historicidad de cualquier yo. De hecho, si como afirma Volpi el yo es una novela que escribimos lentamente a la lo largo de nuestra vida, entonces auto/ficción sería el concepto que, por la inclusión de la barra que une y separa los dos términos, llama la atención no hacia una situación autoevidente que definiría un género cuya particularidad sería la ficcionalización de la instancia narrativa que asume la autoría de lo narrado, por oposición a textos que serían incapaces de ficcionalizar el yo; la barra llama la atención sobre una situación de inestabilidad fundamental y previa al acto de escritura que luego se inmiscuirá en cualquier género textual, pues ella misma, la auto/ficción, no puede ser un género o un subgénero si la entendemos de este modo.

En la novela El orden del mundo el género que permite redimensionar la auto/ficción es el diario; espalda con espalda, el manuscrito de Stahl y el de Sanchiz comparten elementos biográficos y ficcionales y remiten a cada uno de los elementos que componen el concepto que separamos con una barra: "El diario, de hecho, está tan plagado de hechos fantásticos que no hay más remedio que entenderlo completo como una obra de ficción, por 
más que yo crea recordar algunas de las imágenes que invoca" (Sanchiz, 2017, 91).

Otro ángulo de abordaje teórico de la autoficción que nos interesa considerar para comprender El orden del mundo y, de forma más general, algo que sería clave en todo el Proyecto Stahl, está dado por el problema de la relación entre memoria y verdad tal como lo analiza Vásquez Rodríguez en el artículo "Condición de verdad y ficción (literaturas del recuerdo y autoficción)” cuando afirma que:

(...) la imagen mnemónica resulta irrepresentable. En otras palabras, no es posible concebir el recuerdo como representación icónica, como una fotografía o como una sucesión de imágenes, al estilo del filme, pues el recuerdo como imagen mental es proporcional al proceso que solo ve el sujeto que recuerda, y esto es fundamental para asumir el componente cognitivo y emocional de tal recuerdo y sus asideros en la relación de recuerdo y verdad. Con todo, resultaría paradójico asumir una naturaleza preponderantemente fidedigna, legítima e inequívoca del recuerdo, pues en sus reconstrucciones relatadas, un recuerdo se ve condicionado por otros aspectos (narrativos, emocionales, modales, formales) que se introducen con el relato mismo para difuminar sus condiciones de verdad. (Vásquez Rodríguez, 2014, p.1577, cursiva en el original)

Si bien Vásquez Rodríguez reflexiona sobre autoficción y verdad con relación a relatos de traumas que están mucho más cerca de lo que llamamos testimonio, es evidente que su análisis interviene en todo el campo de lo autoficcional; de hecho, la tradición de literatura testimonial en América 
Latina es fundamental para el desarrollo de la creciente presencia del yo en la literatura a partir de los años 1970 hasta hoy, y lo es porque constituye un corpus relevante para el estudio de las relaciones entre memoria y verdad.

El caso de Uruguay, por ejemplo, es didáctico en relación con un proceso de expansión de lo autoficcional a partir de una toma de conciencia de que el testimonio, que surge sobre todo como consecuencia de la cárcel política, tiene una gran dosis de construcción ficticia del yo, la cual, no obstante, muchas veces se presenta como una unidad sin fisuras que reúne al autor, al narrador y al personaje central de cada obra. Condiciones específicas de enunciación donde la duda, la mentira o la fabulación implican un problema ético con relación a la verdad juegan, en un primer momento, un papel fundamental en la creencia y postulación de un testimonio que narraría los hechos y al yo en los hechos confiando en que se los narraría tal como aquellos sucedieron y tal como le sucedieron a dicho yo. Ahondar en las especificidades de los problemas que plantea el testimonio no es posible aquí por una cuestión de espacio. Personalmente hemos analizado en otro momento las características de este testimonio y hemos propuesto que, en Uruguay, El furgón de los locos, de Carlos Liscano, publicado en 2001, puede ser leído como un episodio clave de la deconstrucción y ampliación del espectro de la presencia del yo en una obra que, con ser testimonial, es profundamente literaria en su sentido de enajenación del yo autoral (Chiappara, 2011). Gabriel Peveroni, otro escritor uruguayo clave en la actualidad, que crece durante la dictadura, también está tocado, aunque sea de lejos y de otro modo, por esta relación entre lo testimonial 
y lo ficcional, y ello se nota en el arco que acaban trazando su primera y hermosa novela La cura, de 1997, y Tango que me hiciste mal, un libro de género híbrido, publicado en 2017, que reúne autoficción y exoficción a la Emmanuel Carrère.

Si la novela de Sanchiz en pauta en este trabajo, así como todo lo que compone su macronovela, están lejos de los dos modos de lo testimonial que mencionamos, también nos parece que no se puede entender como un corolario o desdoblamiento simple de otra tradición de la autoficción uruguaya mucho más importante como referencia para su generación y las posteriores. Nos referimos a lo que supuso y todavía supone la publicación de La novela luminosa, de 2005, precedida por El discurso vacio, de 1996, donde Mario Levrero comienza a incursionar por una forma muy particular de autoficción, si bien en realidad, como dice Alejandro Zambra, Levrero se inicie en ella aún más tempranamente, ya que es una "(...) ruta que en realidad comienza diez años antes con Diario de un canalla, [escrito entre 1986 y 1987 en su etapa en Buenos Aires] un texto que según Elvio E. Gandolfo es el momento-bisagra de Levrero." (Zambra, 2012, p.49). Su caso, con ser clave para la idea conceptual de autoficción que problematiza el binomio memoria y verdad, en particular en el Río de la Plata, aunque su área de influencia siga en crecimiento, no puede ser tomado ni como la medida de lo que propone Sanchiz, ni ser descartado como influencia en algún grado.

En El orden del mundo a Sanchiz parece interesarle problematizar algo que puede ser entendido si se observa la relación que une y separa los 
dos elementos del concepto autoficción entendido como auto/ficción. Esta intervención semiótica que modifica el concepto de Doubrovsky nos acerca a una posible manera de comprender la autoficción en esta novela que nos hace sugerir que desistamos de entenderla como subgénero y que nos alienta a entenderla como modus operandi, el cual depende en buena medida de la lectura, ya que los corpus susceptibles de ser analizados bajo lo autoficcional son virtualmente mucho más vastos que lo que podríamos imaginarnos, como se puede constatar en la tendencia creciente a dilatar las fronteras de lo que se entendió inicialmente como autoficción, inclusive yendo hacia atrás en la historia e incluyendo obras ficcionales de la tradición escritas mucho antes y muy lejos de la llamada crisis del sujeto.

En este sentido, Vincent Colonna propone en su tesis de 1989 (L'autofiction. Essai sur la fictionalisation de soi en littérature) y luego en un libro de 2004 (Autofiction \& autres mythomanies littéraires) una clasificación tripartita de lo autoficcional que retoma Javier Ignacio Alarcón en el artículo "Una autoficción sin identidad: reflexiones en torno a la autoficción especular.":

La primera, la autoficción fantástica, es un caso extremo en el cual el autor introduce un personaje que parece ser él mismo en una historia completamente inverosímil: en este caso no hay confusión entre lo que es real y lo que es ficticio, pero el protagonista sigue siendo, a pesar de su carácter fantástico, una referencia al autor. (Alarcón, 2014, p.2171) 
Luego, Vincent Colonna menciona una autoficción biográfica, que considera clásica y, por fin, una especular, que la vincula al teatro (foco central de su artículo). Pero nos interesa retomar la idea que propone Colonna de una autoficción fantástica, ya que creemos que recubre en parte, no totalmente, lo que supone la relación con el yo autoral de Sanchiz en El orden del mundo.

Como puede constatarse en la última cita textual, Colonna da por sentado que en la autoficción fantástica el problema de la confusión entre lo real y lo ficticio desaparece ya que "(...) no hay confusión entre lo que es real y lo que es ficticio." (Colonna, 2014, p.2171). Tal vez la califique como "caso extremo". Por supuesto que este predicado no nos convence porque no corresponde a algo plausible en la lectura que hacemos de los cuentos y novelas del Proyecto Stahl y en particular de El orden del mundo. De un modo más amplio, inclusive, dicho predicado no es adecuado para pensar la presencia de lo autoficcional en la ficción novelesca y en la literatura fantástica en particular. Creemos que el problema está nuevamente en la decisión, esta vez de Colonna, de tomar la autoficción como un subgénero e intentar definirla como tal. Sin embargo, lo autoficcional creemos que tiene una dimensión que escapa al control del escritor que produce un manuscrito y esto no puede ser descartado. Proponemos pensar que, en parte, funciona como algo que se autoinstala en el texto, así como se autoinstalan cookies (preferencias) en el sistema de una computadora o como se producen bugs (errores) en el código de un programa, lo cual permite evocar la vieja cuestión de la representación de sí desde la perspectiva que 
lo propone en Más allá del bien y del mal Nietzsche (1996, 38) cuando afirma que: "El mayor error consiste en admitir un alma que reproduce, reconoce, etc. No depende de mí hacer venir el recuerdo. Aquí el yo es impotente al igual que en lo referente a la aparición de un pensamiento." En conclusión, la barra en auto/ficción señala la inestabilidad, la opacidad y la reciprocidad constitutivas entre los dos elementos del concepto. La manera como empieza El orden del mundo nos parece especialmente significativa para que se entienda esto: "Hace muchos años, en un mundo muy lejano, mis padres me compraron los primeros fascículos de Los Viajes y La Enciclopedia del Mar, de Jacques Cousteau (...).” (Sanchiz, 2017, p.7)

Abertura de relato fantástico y de aventuras que se enraíza en una fórmula que trasvasa la escritura y abraza la tradición del cuento oral. El primer párrafo de la novela cumple el papel de marco a una historia que protagonizará Stahl con una buena medida de recuerdos de Sanchiz, aunque la mediación del inevitable relato, de una nueva camada agregada al autor, no permita que se sepa a ciencia cierta cuánto hay de alguna forma de perlaboración de la memoria.

De los tres capítulos que dividen la novela, el primero es donde hay un mayor volumen de recuerdos de la infancia de Sanchiz, que vienen a formar parte del magma narrativo que derretirá la memoria y fundirá las ficciones que constituyen al yo con las ficciones que constituyen a Federico Stahl. Pero antes de que se derrita, la memoria es innegable material biográfico reciclado en la usina de la literatura. La forma como narra Sanchiz en esta primera parte de la novela sugiere un procedimiento al que parece recurrir 
para entrar en ese universo narrativo al tirar del hilo de los recuerdos, los cuales funcionan como un portal para ese mundo fantástico (esa catedral, dirá hacia el final de la novela el narrador) que levanta poco a poco, y es un nodo fundamental a partir del cual deriva esta historia:

Mi personaje, entonces, y aquí estoy haciendo no otra cosa que intentar comprender por qué escribí ese diario como una novela, como una ficción, podría pensarse como la encarnación de ciertos procesos que entendí inevitables en la isla (...). Los conceptos atraídos por este personaje (...) pueden pensarse como construcciones necesarias, funcionales a la gran metáfora que leo en la isla, al aparato conceptual que, en ese lugar último del mundo, necesité construir como quien erige, y así lo dice el diario en las últimas páginas, una catedral con todos los restos disponibles, con toda la basura de la isla. (Sanchiz, 2017, p.135-136)

Abocados a explicar lo que proponemos al desplazar semióticamente autoficción en este trabajo, concluimos que, en El orden del mundo, Sanchiz acaba ofreciendo la posibilidad de entender mejor la génesis del narrador del proyecto Stahl. En definitiva, es en esta novela donde mejor se da el procedimiento de imbricación entre lo bío y lo gráfico, lo bío/gráfico, que nos parece que justifica el uso de auto/ficción.

\section{REFERENCIAS BBLLIOGRÁFICAS}

Alarcón, Javier Ignacio. "Una autoficción sin identidad: reflexiones en torno a la autoficción especular.” In: Casas, Ana. (Ed.) El yo fabulado. Nuevas aproximaciones críticas a la autoficción. Madrid: Iberoamericana-Vervuert, 2014, e-book Kindle. 
Arroyo Redondo, Susana. "El diálogo paratextual de la autoficción”. In: CASAS, Ana. (Ed.) El yo fabulado. Nuevas aproximaciones críticas a la autoficción. Madrid: Iberoamericana-Vervuert, 2014, e-book Kindle.

Casas, Ana. (Ed.) El yo fabulado. Nuevas aproximaciones críticas a la autoficción. Madrid: Iberoamericana-Vervuert, 2014, e-book Kindle.

Chiappara, Juan Pablo. Ficciones de vida. La literatura de Carlos Liscano. Montevideo: Ediciones del Caballo Perdido, 2011.

"La vista desde el puente de Ramiro Sanchiz: una apuesta por lo fantástico más allá del realismo post y transnacional." In: Revista EstudosLinguisticos e Literários, Salvador: 2017, v. 1, p.26-37, 2017.

"El proyecto Stahl y la novela Nadie recuerda a Mlejnas: nuevas perspectivas literarias y culturales en el Uruguay del siglo XXI.” In: Almeida de Freitas, Luciana Maria et al. (Org.) Anais do VIII Congresso Brasileiro de Hispanistas. Estudos de literatura e cultura. Rio de Janeiro: ABH, 2016, pp. 516-524, e-book. Disponible en <https://drive.google.com/file/d/0B_fPPam93xDcE5nYTNYQ3pWZzg/view> Consultado el: 2 mayo. 2018.

Cusset, François. Teoria francesa. A influência de Foucault, Derrida, Deleuze \& Cia. Trad. Fátima Murad. Porto Alegre: Artmed, 2008.

Nietzsche, Friedrich. Más allá del bien y del mal. Madrid: Alianza editorial, 1996. Maingueneau, Dominique. O contexto da obra literária. Trad. Maria Appenzeller. 2. Ed. São Paulo: Martins Fontes, 2001, 202 p.

Le discours littéraire: Paratopie et scène d'énonciation. Paris: Armand Colin, 2004. 262 p.

Pérez Castillo, Pablo; Rodríguez López, Araceli. (Coord.) Escrituras del yo: conjeturas. Ciudad de México: Universidad Autónoma de Querétaro \& Ediciones Eón, 2013, e-book Kindle.

Preciado, Beatriz. Manifesto contrassexual. Práticas subversivas de identidade sexual. São Paulo: Editor N-1, 2014.

Sanchiz, Ramiro. El orden del mundo. La Paz: Editorial El Cuervo, 2014. 
El orden del mundo. Montevideo: Editorial Fin de Siglo, 2017.

Schmitt, Arnaud. "La autoficción y la poética cognitiva”. In: Casas, Ana. (Ed.) El yo fabulado. Nuevas aproximaciones críticas a la autoficción. Madrid: Iberoamericana-Vervuert, 2014, e-book Kindle.

Vásquez Rodríguez, Gilberto. "Condición de verdad y ficción (literaturas del recuerdo y autoficción)”. In: Casas, Ana. Elyo fabulado. Nuevas aproximaciones críticas a la autoficción. Madrid: Iberoamericana-Vervuert, 2014, e-book Kindle.

Volpi, Jorge. Leer la mente. El cerebro y el arte de la ficción. México: Alfaguara, 2011.

Zambra, Alejandro. No leer. Buenos Aires: Excursiones, 2012. 